\title{
Inhibition of cancer promoting proteins
}

\begin{abstract}
The present document is a brief opinion article on the inhibition of cancer promoting proteins. For this, a bibliographic review of indexed scientific articles was carried out, where the researcher contrasts his ideas with those of other authors. It is concluded that the therapeutic applications directed to the inhibition of proteins that promote neoplasms, will allow a significant reduction of the appearances of malignant tumors in patients with remission.
\end{abstract}

Keywords: cancer, oncogene, protein
Volume 4 Issue 4 - 2018

\author{
José Luis Corona Lisboa \\ Francisco de Miranda National Experimental University, \\ Colombia
}

Correspondence: José Luis Corona Lisboa, Francisco de Miranda National Experimental University, Boat Neighborhood,

15-48, Tibú, Norte de Santander, Colombia, Tel (+57)

3209183778,Email joseluiscaronalisboa@gmail.com

Received: August 03, 2018 | Published: November 01, 2018

\section{Development}

Cancer cells are defined as atypical units whose mechanism of genetic replication have been altered by various causes, so their reproduction is uncontrolled. ${ }^{1}$ However, for this to happen they need the activation of certain proteins that allow their activation and survival behave as they do because, favoring the activation of oncogenes, that is, nucleotide sequences capable of forming tumors (neoplasms).

Currently, molecular medicine and biochemistry are in the constant search to activate selective oncogene blockers, to prevent the formation of malignant tumors in patients with high potential to develop cancer, and for those in whom they do not yet present an apparent symptomatology. ${ }^{2}$

To this end, researchers have manufactured various synthetic compounds in laboratories to try to inhibit oncogenic proteins and in some cases, experiment with drug synergies to obtain better results. Such is the case of some leukemias (cancer in the blood) caused by genetic alterations that lead to translocations. This favors the enzymatic activation of the tyrosine kinase ABL, which binds with another oncogene (BRC) to form an unusual chimeric gene (BCRABL). ${ }^{3}$

Blood progenitor cells with this type of chimerism show uncontrolled and aggressive cellular activity. Consequently, scientists created a drug called imatinib, which inhibits the enzymatic activity of $\mathrm{ABL}$, having great success in the majority of patients treated with the drug. This allowed us to deduce that the inactivation of a single oncogene allows to progressively stopping the abnormal multiplication of these cells. However, treatments for cancer are prolonged and in many cases for life, which induces the mutation of some portions of these oncogenes, creating resistance to the drug. ${ }^{4}$ This represents a major problem, since medicines must be improved and new generations created to face these pathologies.

According to the postulates of Martin \& Domingo, ${ }^{5}$ it is important to know the natural physiological mechanisms of the body to fight cancer, and this includes research from the cell cycle. For these researchers one of the keys is to act on the basis of reproduction itself. When apoptosis fails, a series of cancer inhibiting proteins unfolds from the nucleus. One of them is anticyclins, whose function is to delay the cycle to give the cell time to activate the repair mechanisms of the genome. Additionally, nucleotide excision repair (NER) complex proteins that localize damaged DNA sectors, wind the helix, exclude the affected DNA segment and incorporate the correct sequences.

This represents the other side of the coin in the fight against cancer, because if drugs are made that contribute to the activation of the suppressor proteins from the cell nucleus, we would win an important battle against the different types of carcinomas. There are several tumor suppressor genes (GST, NF2, P53, PRB1, among others) apart from those mentioned above. ${ }^{6}$ If the investigations are directed towards the molecular origin of uncontrolled cell reproduction and the specific forms of biochemical manifestation of more common cancers, we would be working a more suitable path.

For specialists it is not an easy task, because research takes several years in some cases, which are vital for patients with cancer. I believe that a greater professional and ethical conscience should be taken at this point and, above all, to provide greater economic resources to advance in the design of more suitable therapeutic strategies that allow a better quality of life for these patients.

The task is not easy, but neither is it impossible, with effort and dedication we can go ahead and obtain better results to prevent the advance of this terrible pathology that takes the lives of thousands of people around the world.

\section{Acknowledgements}

None.

\section{Conflicts of interest}

Author declares that there is none of the conflicts.

\section{References}

1. Campisi J. Senescent cells, tumor suppression, and organismal aging. Cell. 2005;120(4):513-522.

2. Weinberg RA. The Biology of Cancer. 1st ed. In: Invasion and Metastasis. 2007:1-73.

3. Clarke MF. At the root of brain cancer. Nature. 2004;432(7015):281-282.

4. Wang JCY, Dick JE. Cancer stem cells: lessons from leukemia. Trends Cell Biol. 2005;15(9):494-501.

5. Martín M, Domingo J. Carcinogénesis. Salud Publica Mex. 2011;53:405-414.

6. Brandan N, Juaristi J, Aguirre V, et al. Oncogenes y genes supresores de tumores. Facultad de Medicina. 2013. 